\title{
On the Sensitivity of a Residual Circulation Model to Differences in Input Temperature Data
}

\author{
Paul D. Guthrie and Charles H. Jackman \\ NASA Goddard Space Flight Center, Greenbelt, Maryland \\ TOM L. KUCSERA \\ Applied Research Corporation, Lanham, Maryland \\ JOAN E. ROSENFIELD \\ NASA Goddard Space Flight Center, Greenbelt, Maryland
}

\begin{abstract}
The residual mean circulation (RMC) formulation of zonally averaged transport in the middle atmosphere produces a circulation which depends on the distributions of net diabatic heating and temperature. We have derived such circulations from two temperature data sets, National Meteorological Center (NMC) and Limb Infrared Monitor of the Stratosphere (LIMS), using the same radiative transfer code (Rosenfield et al., 1987). We have used these circulations to transport $\mathrm{N}_{2} \mathrm{O}$ in a photochemical model. The circulations and the resulting $\mathrm{N}_{2} \mathrm{O}$ distributions are notably different during the northern hemisphere winter, with that based on the NMC temperatures producing too much upward transport in the tropical stratosphere as judged by comparison with the stratospheric and mesoscale sounder data. The experiment demonstrates that model calculations, in general, and perturbation assessments, in particular, are likely to be quite sensitive to the choice of input temperature data (where this is not computed self-consistently). It also reveals what appears to be a seasonally dependent bias in NMC zonally averaged temperatures with respect to those obtained from the LIMS instrument during 1978/1979.
\end{abstract}

\section{INTRODUCTION}

In the past decade or so the study of the distribution of trace species in the atmosphere has come to depend much on zonally averaged models based on the "residual mean" circulation [Andrews and McIntyre, 1976; Edmon et al., 1980; Garcia and Solomon, 1983; Rogers and Pyle, 1984; Guthrie et al. 1984; Isaksen and Stordal, 1986]. The main advantage claimed for this formulation of transport over the more intuitive "classical Eulerian" mean transport is avoidance of the eddy-mean-flow cancellation problem [e.g., Harwood and Pyle, 1975; Plumb and Mahlman, 1987] and thus greater confidence that the computed circulation accurately portrays the transport of trace species in the real atmosphere. Given perfect data, the approaches are formally equivalent, but given actual circumstances, many authors have argued that the residual formulation is more easily analyzed and less sensitive to uncertainties in the input data.

This is not to say, however, that residual mean circulations (RMCs) are insensitive to differences in their input data. The fundamental observable on which these circulations are based is the zonal mean temperature as a function of altitude, latitude, and time. This enters into the calculation of the vertical wind component both directly and through the calculation of the zonal mean net heating, which is, in general, a nonlinear function of temperature. In this paper we wish to illustrate the sensitivity of this calculation to the temperature data set selected as input. The resulting

Copyright 1990 by the American Geophysical Union.

Paper number 89JD01562. 0148-0227/90/89JD-01562\$05.00 uncertainty in the computed RMC advective wind fields may lead to substantial uncertainties in perturbation assessments in models.

\section{Calculation of RMC Winds}

The now well-known basic equations for wind fields in the RMC formulation are Conservation of zonal momentum

$$
\frac{\partial \bar{u}}{\partial t}-f \bar{v}^{*}=\frac{1}{\rho_{0} a \cos \phi} \nabla \cdot F+(\text { other terms) }
$$

Thermal wind balance equation

$$
f \frac{\partial \bar{u}}{\partial z}=-\frac{S}{a} \frac{\partial \bar{\Theta}}{\partial \phi}
$$

Thermodynamic equation for potential temperature

$$
\frac{\partial \bar{\Theta}}{\partial t}+\bar{w}^{*} \frac{\partial \bar{\Theta}}{\partial z}+\frac{\bar{v}^{*}}{a} \frac{\partial \bar{\Theta}}{\partial \phi}=\bar{Q}-D_{H}
$$

Continuity equation

$$
\frac{1}{a \cos \phi} \frac{\partial}{\partial \phi}\left(\bar{\nu}^{*} \cos \phi\right)+\frac{1}{\rho_{0}} \frac{\partial}{\partial z}\left(\rho_{0} \bar{w}^{*}\right)=0
$$

Here $\phi$ is latitude, $z$ is $\log$ pressure altitude, $a$ is radius of Earth, $\rho_{0}$ is density, $f$ is Coriolis parameter, $S$ is stability, $\bar{\Theta}$. is potential temperature, $\bar{u}$ is zonal mean velocity, and $\bar{w}^{*}$ and $\bar{v}^{*}$ are vertical and meridional components of the RMC winds, respectively. Terms appearing on the right-hand side 

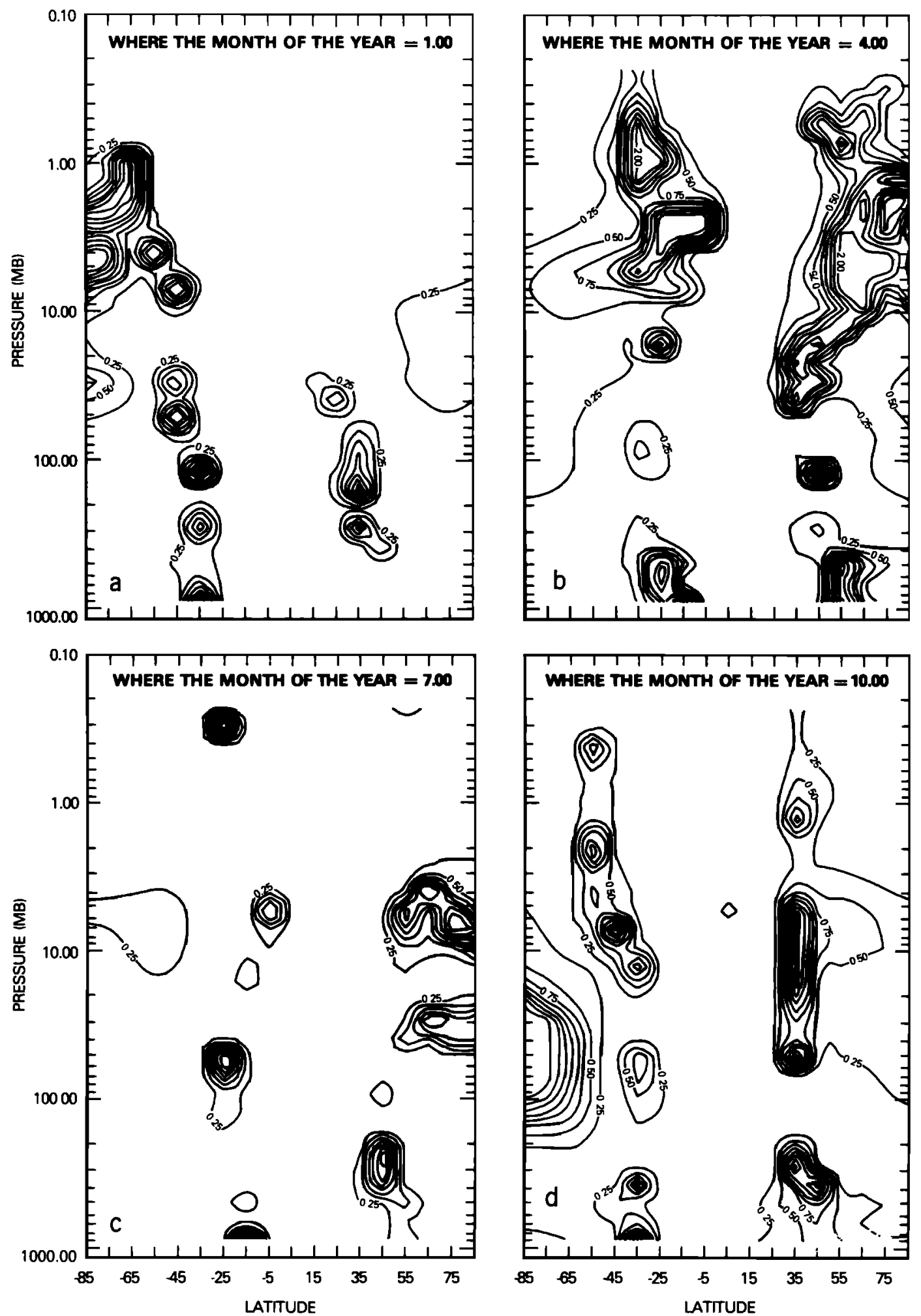

Fig. 1. Ratio of potential temperature tendency to net heating rate from NMC. Four-year average for 12 calendar months. Contour interval is 0.25. (a) January, (b) April, (c) July, (d) October.

of (1) and (3) are often called the forcing terms; $\bar{Q}$ is zonal mean net heating, $\nabla \cdot \mathrm{F}$ is divergence of the Eliassen-Palm flux (or momentum forcing), and $D_{H}$ is diffusive heating due to small-scale wave motions. ( $D_{H}$ is zero in the formal RMC derivation, which applies to the cancelling effects of heat transport by the mean circulation and large-scale eddies.)
The treatment of these forcing terms is central to the development of any RMC model.

One approach (exemplified by Dunkerton [1978]) is to set the momentum forcing, the diffusive heating, and the time derivative terms in (1) and (3) to zero, often termed the diabatic circulation approximation. The last term on the 

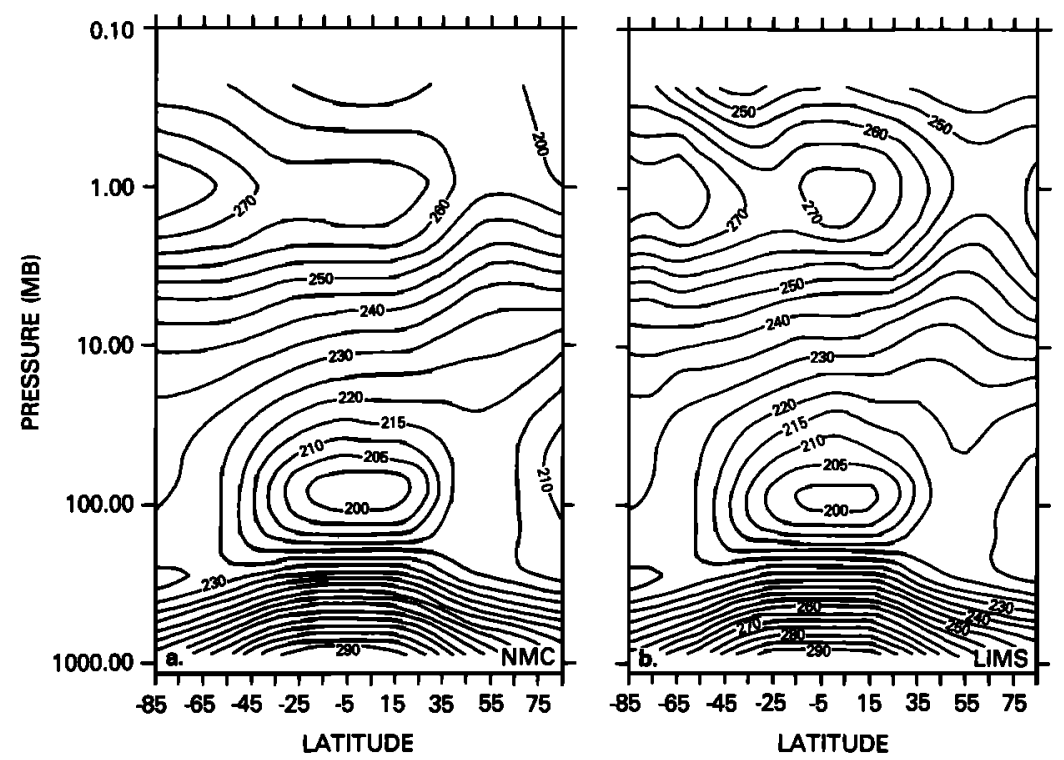

Fig. 2. Temperature fields (in degrees) for February. Contour interval is 5.00. (a) NMC, (b) LIMS.

left-hand side of (3) is, in general, small in the stratosphere and is also neglected, yielding

$$
\bar{w}_{\text {diab }}=\bar{Q} / \frac{\partial \bar{\Theta}}{\partial z}
$$

for which $\bar{v}^{*}$ may be obtained via (4). The diabatic circulation thus depends only on the temperature, and through $\bar{Q}$, on the distribution of radiatively active molecular species.

Examination of typical temperature data, however, reveals that neglecting the time tendency terms is generally a poor approximation. This is illustrated in Figure 1, based on the 4-year average of National Meteorological Center (NMC) temperatures described by Geller et al. [1984]. The time tendency is approximated by the difference between the temperatures during the following and preceding months at each location in the grid, divided by 60 days. Note that the ratio of the time tendency to the net heating (taken from Rosenfield et al. [1987] and based on the same temperature data set) is greater than 0.5 in much of the grid and often greater than 1 , when the net heating is small.

If one retains the time tendency terms, the winds may again be obtained directly from (3) and (4), or as gradients of the stream function, as outlined by Garcia and Solomon [1983]. In either case, the right-hand side of (1) is not, in general, zero. If the stream function is used, the momentum forcing and/or the "other terms" in (1) must be adjusted to yield a reasonable circulation; if the velocities are obtained directly, then the required momentum forcing associated with the velocity field may be deduced. Because this forcing represents the effect of transience and dissipation of largescale wave motions (departures from the mean flow), it cannot be deduced independently of the mean circulation.

Recent attempts to compute the RMC, and the resulting transport of constituents, from observed temperatures have neglected the direct effects of this momentum forcing on the eddy mixing, and we will make the same approximation in this paper. Thus $K_{y y}$ is set at $2 \times 10^{9} \mathrm{~cm}^{2} \mathrm{~s}^{-1}$ throughout the stratosphere, and $K_{y z}$ is set to zero. Some of the consequences of neglecting these mixing processes (associated with the eddy motions) are addressed by Jackman et al. [1988].

As noted above, there have been several recent attempts to compute the RMC, based on the best available data sets and modern radiation codes. In particular, Rosenfield et al. [1987] computed the RMC from NMC 4-year temperature averages and solar backscattered ultraviolet (SBUV) ozone for 1979 [McPeters et al., 1984], while Solomon et al. [1986] computed the RMC from 7 months of data from the Limb Infrared Monitor of the Stratosphere (LIMS) instrument for both temperature and ozone. These two calculations were made with different radiation codes. Callis et al. [1987] have published a calculation based on climatological temperatures assembled by Barnett and Corney [1985] from a number of satellite-based measurements and on climatological ozone as given by Keating and Young [1985]. Callis et al. also computed the RMC from LIMS data for the specific period October 1978 through May 1979; the radiative transfer code used was again different from those used in the studies mentioned above. Given this diversity of radiative calculations and data sources, it becomes difficult to determine whether differences among these studies arise from the heating codes, from the temperature data, or from the way in which the RMC is obtained from the heating rates. It has also been unclear how differences among RMC calculations affect the subsequent evolution of photochemical models.

\section{The Present Experiment}

In order to focus on the effects of these differing circulations in models, we have performed an experiment in which the heating rates are derived from different data sets using the same radiation code. The net heating was computed using the code described by Rosenfield et al. [1987] (R87 hereafter) for two separate cases. The first is just the case described in that paper, i.e., NMC temperatures and SBUV ozone, but recomputed on our model grid for the 12 calendar months. The second is based primarily on the LIMS measurements of temperature and ozone. Because LIMS did not have global coverage, the temperatures have been aug- 


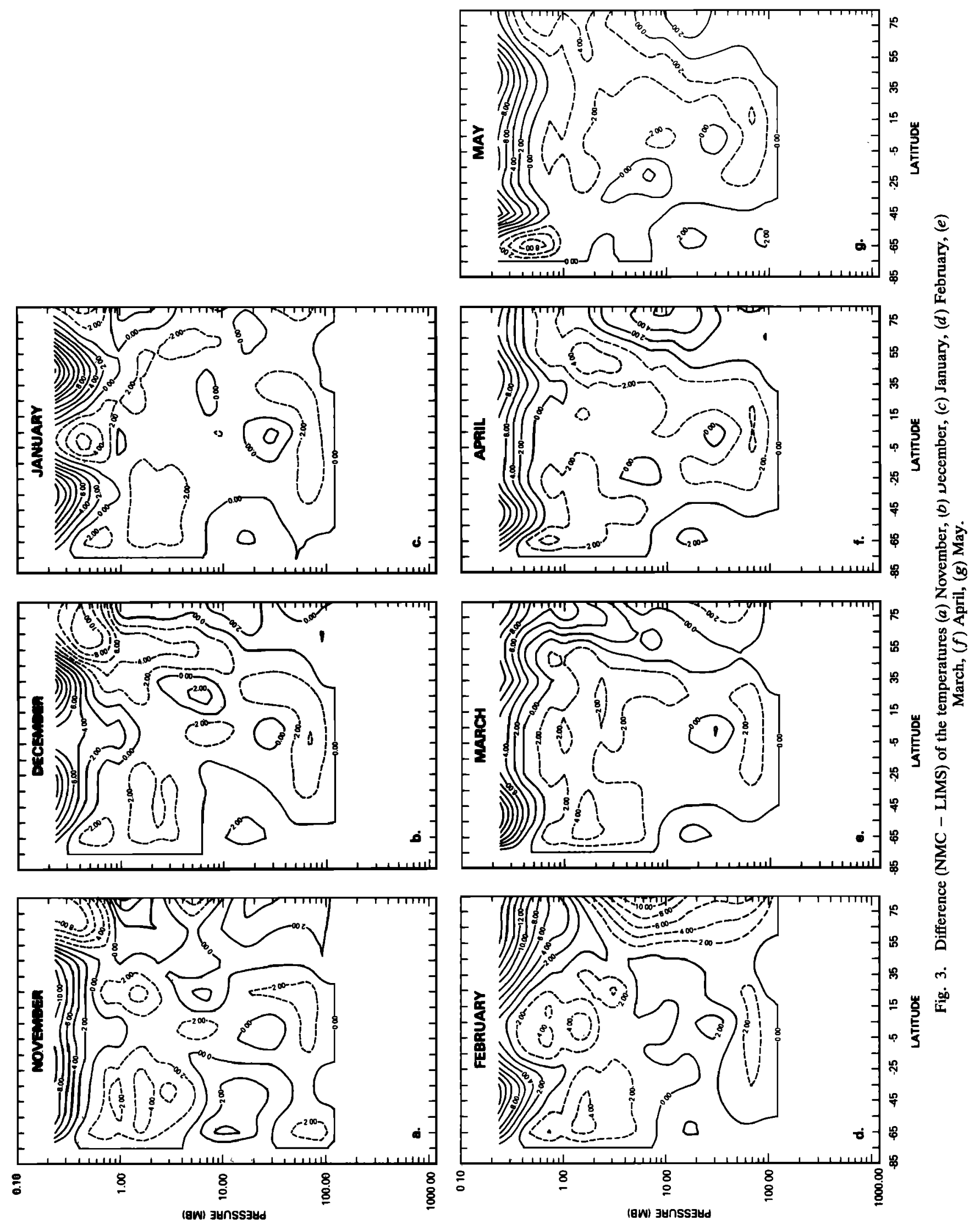



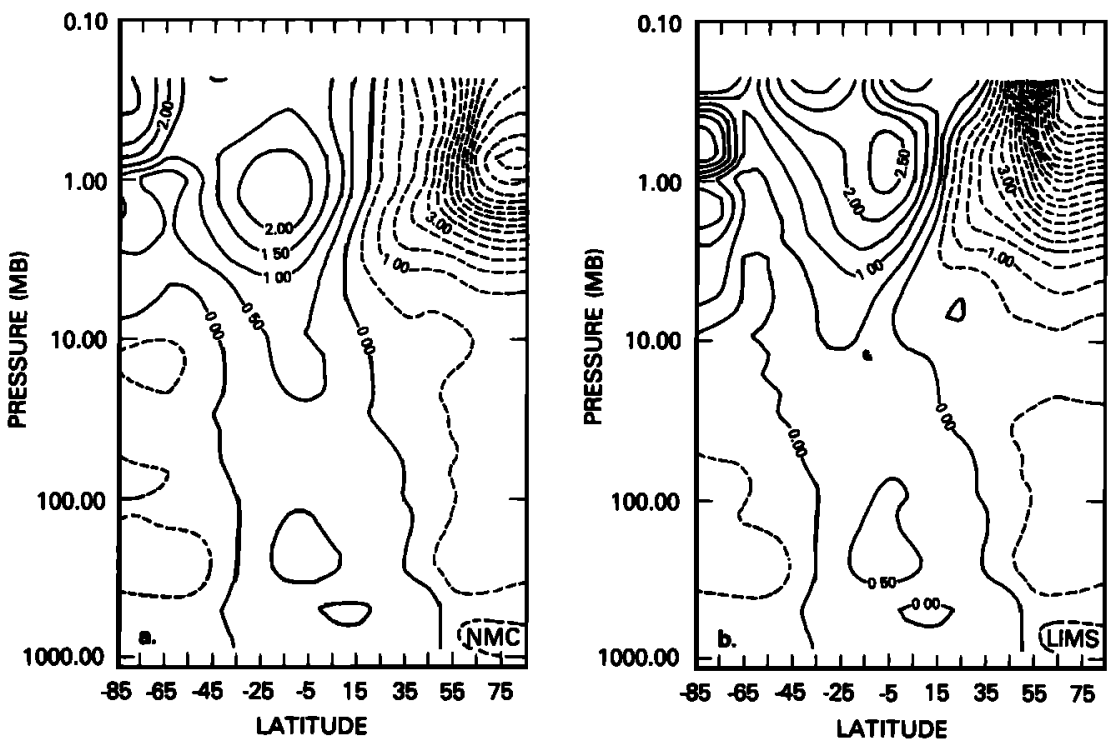

Fig. 4. Net heating rate (in degrees kelvin per day) for December. Contour interval is 0.50. (a) NMC, (b) LIMS.

mented with NMC data from the same period to fill the grid. The temperatures for June-September are obtained by inverting the data for December-March around the equator. These adjustments, as opposed to using the same ozone in both cases or filling in the missing months of LIMS data with NMC values, are motivated by our desire to maintain the difference in vertical resolution between the two data sets. In a later section we discuss tests of the sensitivity of the circulations to these choices.

In both cases, water vapor is specified from LIMS data, and both temperature and a nonradiative diabatic heating rate are specified monthly below the tropopause. The troposphere temperature is taken from the NMC 4-year-average data set and the total diabatic heating is based on the work of Wei et al. [1983].

For each case the net diabatic heating is obtained throughout the grid and adjusted as in R87 to assure zero mean heating on each pressure level. The RMC is then obtained as in the diabatic case but with the differenced temperature tendency subtracted from the heating rate. The temperature and circulations are used to drive a limited-chemistry model [Guthrie et al., 1984] in which $\mathrm{N}_{2} \mathrm{O}$ is used as a tracer. The cases were each run for ten model years and achieved repeating annual cycles in the tracer distributions.

\section{COMPARISON OF RESUlTS}

The input temperature fields for February (arguably the month of maximum discrepancy) are shown in Figure 2. Note that there is a systematic difference with latitude at about 10 mbar, NMC temperatures being about $2 \mathrm{~K}$ warmer in the southern hemisphere, and as much as $10 \mathrm{~K}$ colder in the northern midstratosphere. Similar behavior was noted by Rodgers [1984] in comparing data for specific days. Differ-
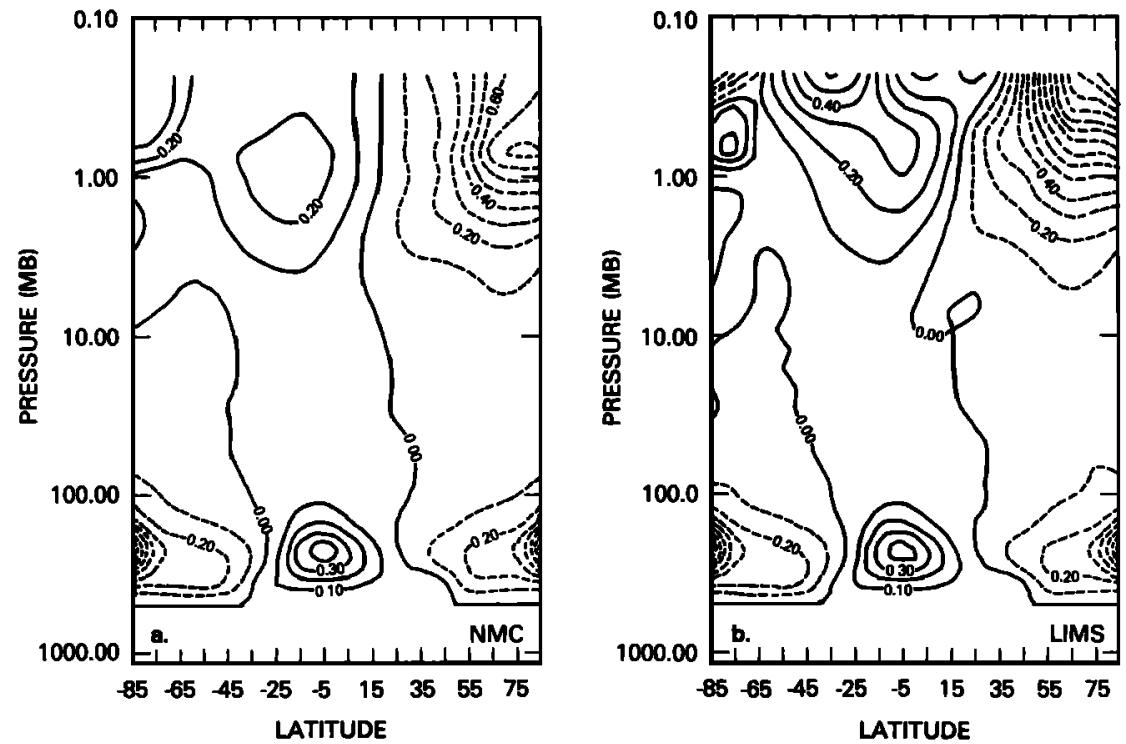

Fig. 5. Vertical RMC velocity (in centimeters per second) for December. Contour interval is 0.10. (a) NMC, (b) LIMS. 

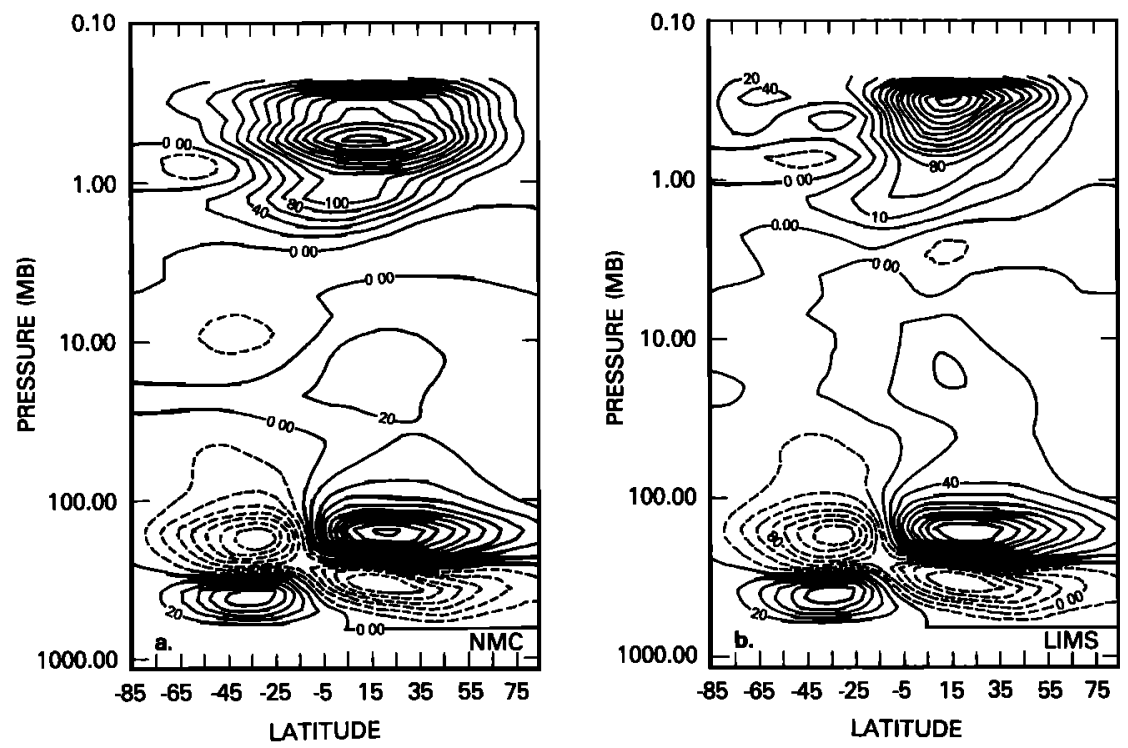

Fig. 6. Meridional RMC velocity (in centimeters per second) for December. Contour interval is 20.00. (a) NMC, (b) LIMS.

ence plots for the entire LIMS period are shown in Figure 3. The structure above 1 mbar in the difference plots is entirely due to the LIMS data and is unresolved in the NMC data. Note that the systematic difference shifts with season, having the opposite sense in February and May. Since the comparison is between a specific time period and a 4-year average, this systematic difference may be simply the effect of interannual variability.

The derived zonal mean net heating rates for the two data sets for December (a more typical month than February) are shown in Figure 4 (recall that they are identical and imposed below the tropopause). The overall morphology is very similar, with the largest differences occurring near and above the stratopause. The RMC velocity fields for the two cases are shown in Figures 5 and 6 for the vertical and meridional components, respectively. The difference in velocity is most pronounced in the meridional component. Note, for instance, the band of positive (Northward) velocity at 20 mbar in the southern hemisphere which occurs in the NMC case but is absent in the LIMS case. In both cases the general high-latitude vertical motion is downward, but the LIMS circulation has a poleward component in this region, while the NMC circulation is downward and equatorward in this thin layer. The NMC case is thus less effective in transporting air downward and poleward from above this layer. The strength of the downward-poleward circulation in this region can have a substantial effect on the latitude dependence of ozone depletion assessments [Solomon et al., 1985; Isaksen and Stordal 1986]. Similar differences occur during other months. From the standpoint of tracer distributions, however, the most important difference is the strength of the upward transport in the tropical stratosphere. The difference here is due to the seemingly small enhancement of the heating in the NMC case over that in the LIMS case, due in turn to the cooler NMC temperatures above $10 \mathrm{mbar}$. As we will see in the tracer distributions, this results in the NMC circulation being stronger than the LIMS circulation in an overall sense, with the period of maximum difference being the northern hemisphere winter season.
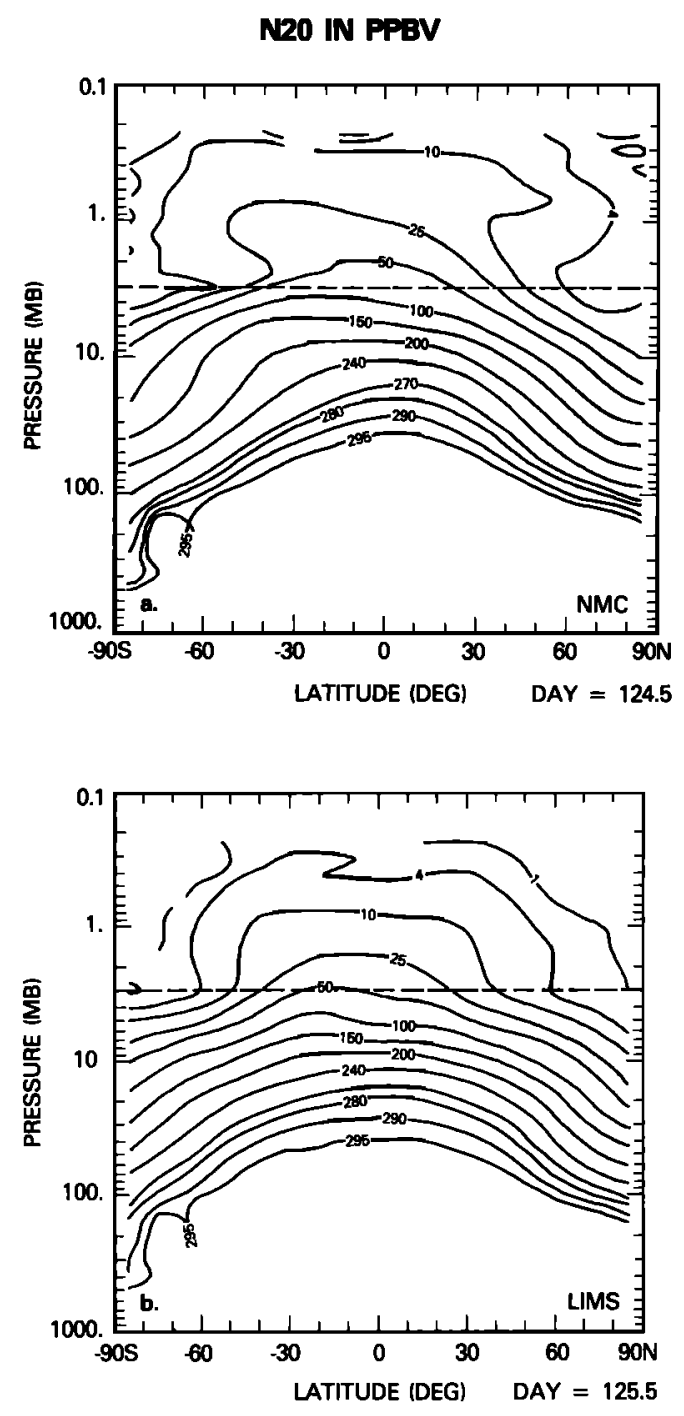

Fig. 7. Northern hemisphere spring $\mathrm{N}_{2} \mathrm{O}$ distributions. (a) NMC, (b) LIMS. 
N20 IN PPBV
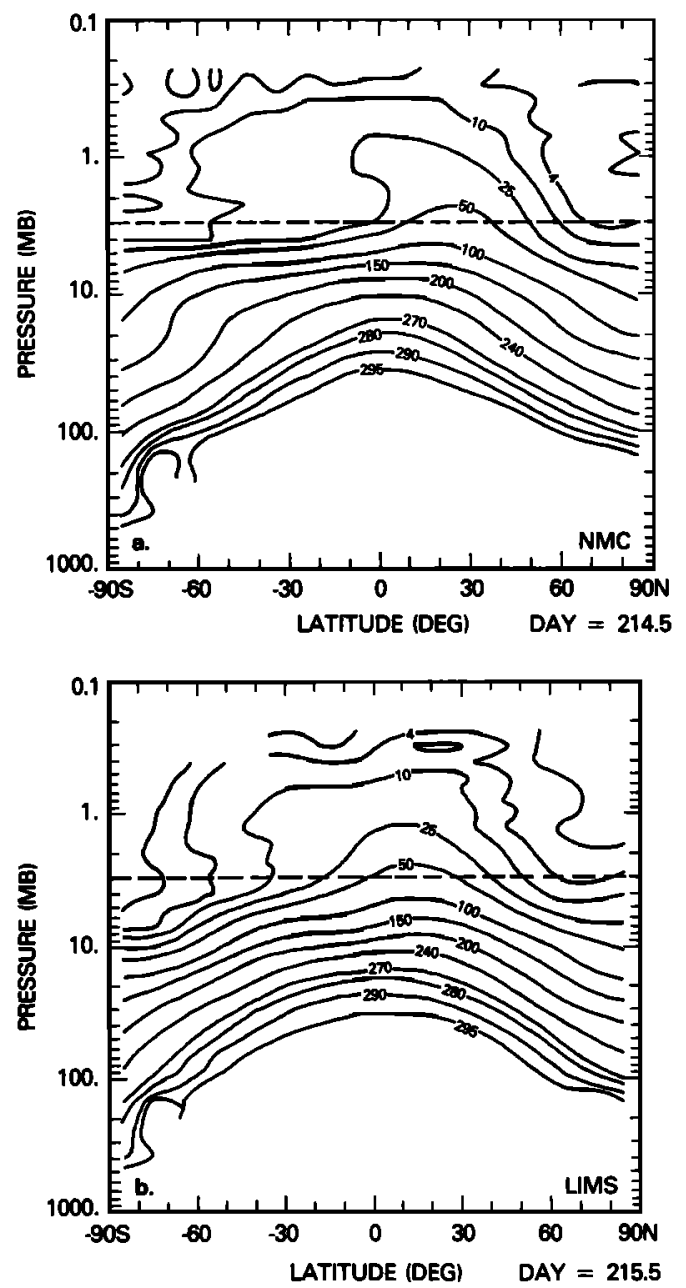

Fig. 8. As in Figure 7 for summer.

\section{Tracer Studies $\left(\mathrm{N}_{2} \mathrm{O}\right)$}

In order to focus on the effects of transport in photochemical models it is often useful to compute distributions of long-lived tracers with the ozone distribution (and thus the local photolytic fluxes) specified at monthly intervals. We have used a version of the Goddard Space Flight Center (GSFC) two-dimensional photochemical model in which the ozone is specified from SBUV data (the same data used in the NMC heating calculation) and $\mathrm{N}_{2} \mathrm{O}$ is injected at the lower boundary at a constant mixing ratio of $300 \mathrm{ppbv}$. The only chemistry is that relating to $\mathrm{N}_{2} \mathrm{O}$ loss, i.e., photolysis of $\mathrm{N}_{2} \mathrm{O}$ and the production and loss of $\mathrm{O}\left({ }^{1} D\right)$. Differences in the $\mathrm{N}_{2} \mathrm{O}$ distributions for separate circulations are then almost entirely due to differences in transport (there is a very slight sensitivity of this chemistry to temperature).

We have run our two cases, NMC and LIMS circulations, each for 10 model years, by which time the $\mathrm{N}_{2} \mathrm{O}$ distributions had reached stable repeating annual cycles. The distributions are compared for 4 months in Figures 7, 8, 9, and 10. In each, panel a represents the NMC case and panel $b$ the LIMS case. The 3-mbar level is noted in each panel by a dashed line. One sees immediately that for most of the year the distributions at and below this level are very similar.
During January, however, the $\mathrm{N}_{2} \mathrm{O}$ mixing ratios at the tropical maximum at 3 mbar differ by a factor of 2 , with associated differences in isopleth slopes extending into midlatitudes in the southern hemisphere. The approximate positions of the 100- and 30-ppbv contours for $\mathrm{N}_{2} \mathrm{O}$ in January 1979 from the stratospheric and mesospheric sounder (SAMS) data [Jones and Pyle, 1984] are shown by the heavy lines in Figure $10 b$. They are in good agreement with the LIMS case (as previously noted in the work of Solomon et al. [1986]), thus in disagreement with the NMC case.

Because the NMC case represents 4-year averaged data, while the LIMS case represents 1978/1979, one is faced with two possible explanations for the winter differences. Either the NMC data set has a seasonally dependent bias, or $1978 / 1979$ was an anomalous winter, as reflected in both the LIMS temperatures and the SAMS $\mathrm{N}_{2} \mathrm{O}$ measurements. The latter possibility has profound implications for model studies, since observations during this time period have been widely used as validation measures for photochemical models.

As another way of evaluating the differences between these two experiments, we can calculate the lifetime of $\mathrm{N}_{2} \mathrm{O}$ in each. The lifetimes derived from this study are shown in
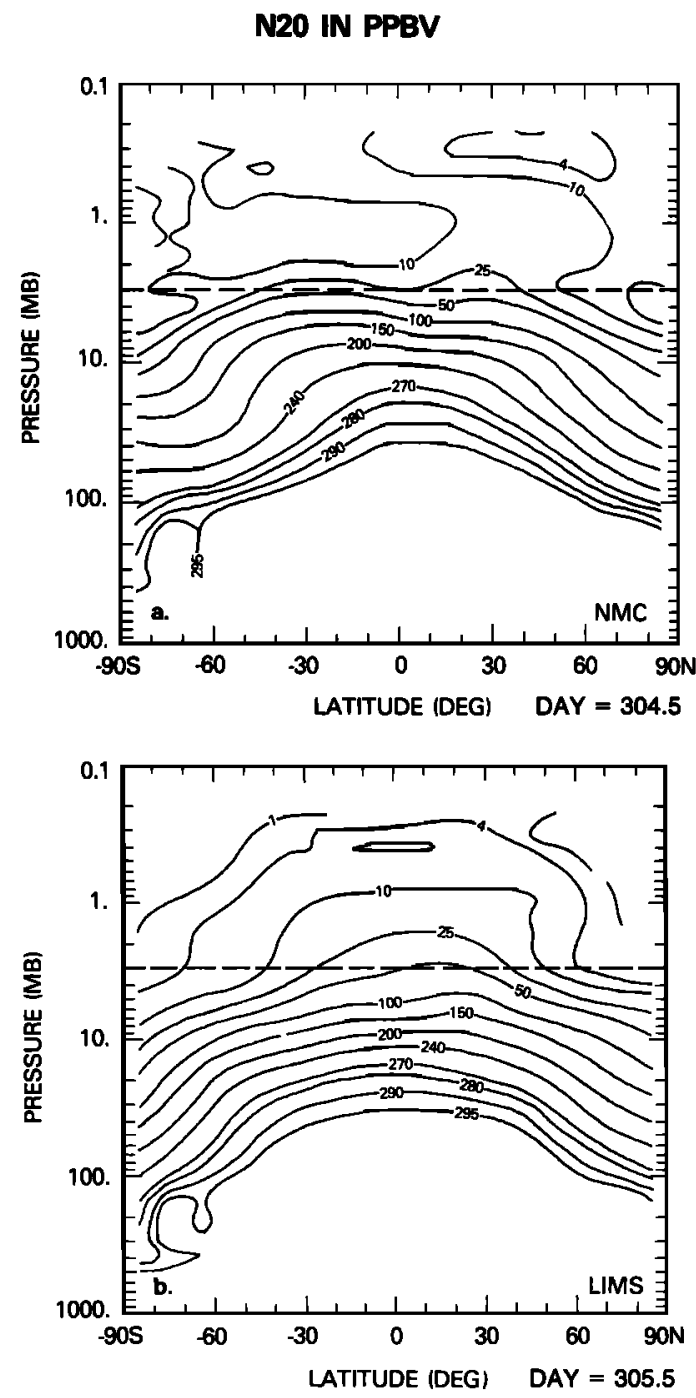

Fig. 9. As in Figure 7 for fall. 

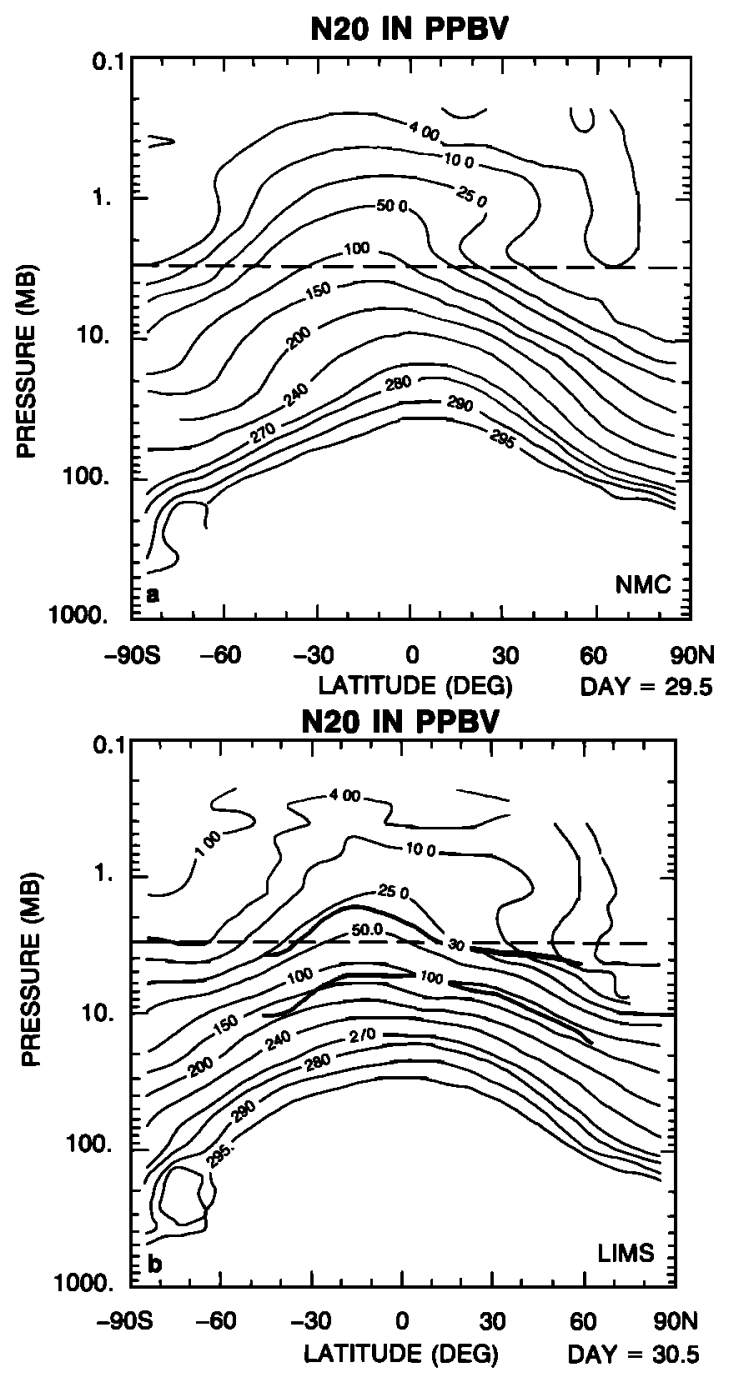

Fig. 10. As in Figure 7 for winter. SAMS data shown by heavy solid lines.

Table 1, along with those from two previous studies. Note that these are mean lifetimes averaged over the model domain. In steady state the circulation transports tracer from the source to the region of rapid loss so that at each level the loss is balanced by the transport in from below, at least in an annually averaged sense. In interpreting lifetimes we associate shorter lifetimes with "stronger" circulations, i.e., a circulation which moves air more rapidly between the source region and the photochemical loss region. The NMC case is the strongest circulation we have examined to date. The so-called "weak" diabatic circulation is that used by Guthrie et al. [1984] and is similar to the circulations used in the chlorine perturbation studies of Isaksen and Stordal [1986]. As may be seen by comparison with the results of Jackman et al. [1988], the difference between the LIMS and NMC cases generally is large compared to the difference due to the presence or absence of spatially variable diffusion coefficients. We have not included the possible effects of breaking gravity waves on vertical mixing in any of our runs. The value of $K_{z z}$ is set at $2 \times 10^{3} \mathrm{~cm}^{2} \mathrm{~s}^{-1}$ throughout the stratosphere. Garcia and Solomon [1985] found this process to become important in two-dimensional model transport only well above 1 mbar. In any case its neglect should not affect the intercomparison of the model runs.

\section{Discussion}

As noted above, there are a number of possible reasons for a discrepancy between the two cases, but they all fall into the categories of systematic bias during the northern hemisphere winter season or of interannual variability which skews the comparison of the 1978/1979 winter with the 4-year averages. Geller et al. [1984] considered the effects of interannual variability in the NMC data set and found substantial variability of stratospheric temperature at high latitudes. However, there is no obviously anomalous year in terms of tropical midstratospheric temperatures (i.e., in the region of the $\mathrm{N}_{2} \mathrm{O}$ anomaly). We have constructed an analogue of the LIMS data set using NMC data from the LIMS period (November 1978 to May 1979). The extrapolation procedures for high latitudes and other months were the same. The January distribution of $\mathrm{N}_{2} \mathrm{O}$ from the model run with this data set is shown in Figure 11. Note that it is much more similar to the NMC 4-year average case than to the LIMS case derived from temperatures measured during the same period. This is especially true at and above the 3 -mbar level in the tropics, where the factor-of-2 discrepancy with respect to SAMS $\mathrm{N}_{2} \mathrm{O}$ remains. This argues against the difference arising from interannual variability.

As noted above, the NMC and LIMS cases differ not only in the temperatures used to generate the circulations but also in the ozone data used to determine the UV heating distributions. At the 3-mbar level in the tropics the ozone data for the two cases differ by slightly less than $15 \%$. However, as noted by an anonymous referee, the relative contributions of the UV and IR portions of the radiative heating and cooling to the net radiative heating vary substantially over the model domain. We have thus undertaken a cross-check experiment. In this experiment we use the LIMS temperature data with the SBUV ozone data to generate hybrid net heating rates and the resulting circulation. The resulting January $\mathrm{N}_{2} \mathrm{O}$ distribution for the model run using this hybrid circulation is shown in Figure 12. We find that changing the ozone distribution to that seen in the SBUV data produces only about a $20 \%$ change in the $\mathrm{N}_{2} \mathrm{O}$ abundance at the 3-mbar level in the tropics; substantially less than the factor-of-2 discrepancy seen between our base NMC and LIMS cases. The bulk of the $\mathrm{N}_{2} \mathrm{O}$ difference is thus clearly attributed to the temperature differences.

Finally, if 1979 was an anomalous year for transport, one would expect it to show up in a variety of tracers. The only multiyear data on tracers in the region of interest is from SAMS for $\mathrm{N}_{2} \mathrm{O}$ and $\mathrm{CH}_{4}$. Jones [1984] showed monthly zonal mean cross sections for $\mathrm{CH}_{4}$ for 1979,1980 and 1981; the differences at 3 mbar in the tropics in December and January are far less than a factor of 2 .

TABLE 1. Lifetime of $\mathrm{N}_{2} \mathrm{O}$

\begin{tabular}{lc}
\hline \multicolumn{1}{c}{ Experiment } & Lifetime, years \\
\hline NMC RMC & 120 \\
LIMS RMC & 137 \\
NMC diabatic (R87) & 122 \\
"Weak" diabatic & 159 \\
\hline
\end{tabular}


N20 IN PPBV

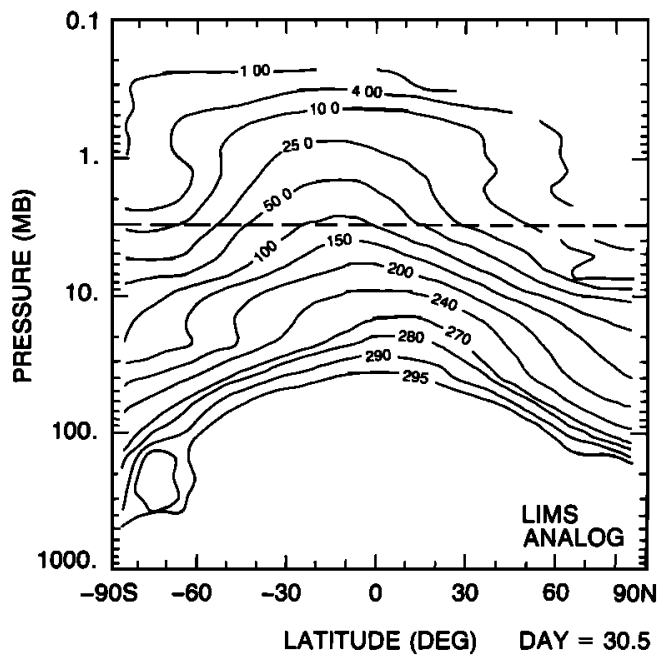

Fig. 11. January $\mathrm{N}_{2} \mathrm{O}$ for the NMC-derived LIMS analogue data set (compare to Figure 10).

We are left, then, with a possible seasonal bias of the NMC data set with respect to the LIMS temperature data. We have no information as to the possible cause for such a bias.

\section{CONCLUSION}

We have produced two calculations of the residual mean circulation based on the same net heating code and the same underlying atmospheric model but two different temperature data sets. The resulting circulations yield similar distributions of $\mathrm{N}_{2} \mathrm{O}$ except during the northern hemisphere winter season. During this time period the tropical midstratospheric mixing ratio for the NMC case exceeds that for the LIMS case by about a factor of 2. The LIMS case is in better agreement with SAMS data for $\mathrm{N}_{2} \mathrm{O}$ during this period.

Reasons for the anomaly could involve either a seasonally dependent bias of the NMC data set or interannual variabil-

\section{N20 IN PPBV}

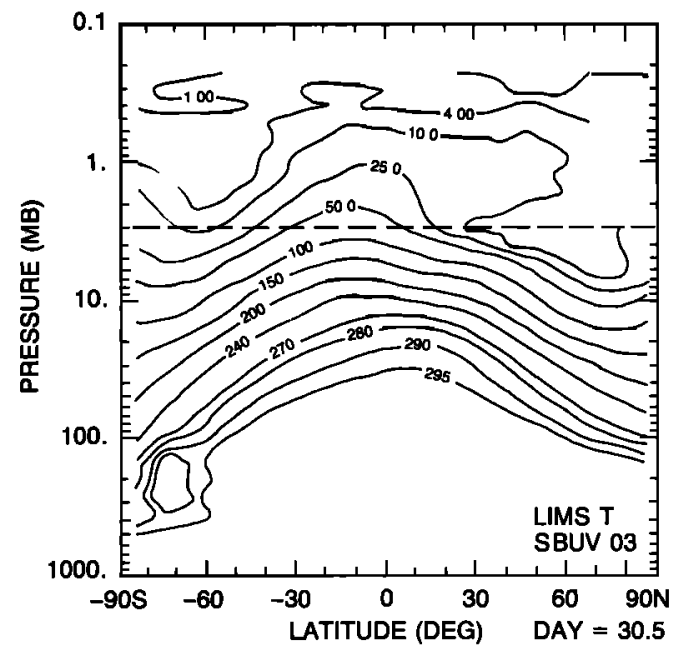

Fig. 12. January $\mathrm{N}_{2} \mathrm{O}$ for the circulation derived from LIMS temperatures and SBUV ozone data. ity causing $1978 / 1979$ to be anomalous with respect to the 4-year average. Preliminary examination of the SAMS $\mathrm{CH}_{4}$ data for other years leads us to suspect a seasonally dependent bias in the NMC temperature data set.

Acknowledgement. Joan E. Rosenfield is a Universities Space Research Association resident associate.

\section{REFERENCES}

Andrews, D. G., and M. E. McIntyre, Planetary waves in horizontal vertical shear: The generalized Eliassen-Palm relation and the zonal mean acceleration, J. Atmos. Sci., 33, 2031, 1976.

Barnett, J. J., and M. Corney, Middle atmosphere reference model derived from satellite data, in Middle Atmosphere Program Handbook, vol. 16, edited by K. Labitzke, J. J. Barnett, and B. Edwards, p. 47, University of Illinois, Urbana, 1985.

Callis, L. B., R. E. Boughner, and J. D. Lambeth, The stratosphere: Climatologies of the radiative heating and cooling rates and diabatically diagnosed net circulation fields, J. Geophys. Res., 92, $5585,1987$.

Dunkerton, $T$., On the mean meridional mass motions of the stratosphere and mesosphere, J. Atmos. Sci., 35, 2325, 1978.

Edmon, H. J., B. J. Hoskins, and M. E. McIntyre, Eliassen-Palm cross-sections for the troposphere, J. Atmos. Sci., 37, 2600, 1980.

Garcia, R. R., and S. Solomon, A numerical model of the zonally averaged dynamical and chemical structure of the middle atmosphere, J. Geophys. Res., 88, 1379, 1983.

Garcia, R. R., and S. Solomon, The effect of breaking gravity waves on the dynamics and chemical composition of the mesosphere and lower thermosphere, J. Geophys. Res., 90, 3850, 1985.

Geller, M. A., M. F. Wu, and M. E. Gelman, Tropospherestratosphere (surface-55 km) monthly winter general circulation statistics for the northern hemisphere-Interannual variations, $J$. Atmos. Sci., 41, 1726, 1984.

Guthrie, P. D., C. H. Jackman, J. R. Herman, and C. J. McQuillan, A diabatic circulation experiment in a two-dimensional photochemical model, J. Geophys. Res., 89, 9589, 1984.

Harwood, R. S., and J. A. Pyle, A two-dimensional mean circulation model for the atmosphere below $80 \mathrm{~km}, Q . J$. R. Meteorol. Soc., 101, 723, 1975.

Isaksen, I. S. A., and F. Stordal, Ozone perturbations by enhanced levels of $\mathrm{CFCs} \mathrm{N}_{2} \mathrm{O}$ and $\mathrm{CH}_{4}$ : A two-dimensional diabatic circulation study including uncertainty estimates, J. Geophys. Res., 91, 5249, 1986.

Jackman, C. H., P. A. Newman, P. D. Guthrie, and M. R. Schoeberl, Effect of computed horizontal diffusion coefficients on two-dimensional $\mathrm{N}_{2} \mathrm{O}$ model distributions, J. Geophys. Res., 93, 5213-5219, 1988.

Jones, R. L., Satellite measurements of atmospheric composition: Three years observations of $\mathrm{CH}_{4}$ and $\mathrm{N}_{2} \mathrm{O}$, Adv. Space Res., 4, $121,1984$.

Jones, R. L., and J. A. Pyle, Observations of $\mathrm{CH}_{4}$ and $\mathrm{N}_{2}$ by the Nimbus 7 SAMS: A comparison with in situ data and twodimensional numerical model calculations, J. Geophys. Res., 89, 5263, 1984.

Keating, G. M., and D. F. Young, Interim reference ozone models for the middle atmosphere, in Middle Atmosphere Program Handbook, vol. 15, edited by K. Labitzke, J. J. Barnett and B. Edwards, p. 205, University of Illinois, Urbana, 1985.

McPeters, R. D., D. F. Heath, and P. K. Bhartia, Average ozone profiles for 1979 from the Nimbus 7 SBUV instrument, J. Geophys. Res., 89, 5199, 1984.

Plumb, R. A., and J. D. Mahlman, The zonally-averaged transport characteristics of the GFDL general circulation/transport model, J. Atmos. Sci., 44, 298, 1987.

Rodgers, C. D., Coordinated study of the behavior of the middle atmosphere in winter (PMP-1) in Middle Atmosphere Program Handbook, vol. 12, edited by C. D. Rodgers, p. 1, University of Illinois, Urbana 1984.

Rogers, C. F., and J. A. Pyle, Stratospheric tracer transport: A modified diabatic circulation model, Q.J.R. Meteorol. Soc., 110, $219,1984$.

Rosenfield, J. E., M. R. Schoeberl, and M. A. Geller, A computa- 
tion of stratospheric diabatic residual circulation using an accurate radiative transfer model, J. Atmos. Sci., 44, 859, 1987.

Solomon, S., R. R. Garcia, and F. Stordal, Transport processes and ozone perturbations, J. Geophys. Res., 90, 12,981, 1985.

Solomon, S., J. T. Kiehl, R. R. Garcia, and W. Grose, Tracer transport by the diabatic circulation deduced from satellite observations, J. Atmos. Sci., 43, 1603, 1986.

Wei, M.-Y., D. R. Johnson, and R. D. Townsend, Seasonal distributions of diabatic heating during the first GARP Global Experiment, Tellus, 35A, 241, 1983.
P. D. Guthrie, C. H. Jackman, and J. E. Rosenfield, Atmospheric Chemistry and Dynamics Branch, Code 616, NASA Goddard Space Flight Center, Greenbelt, MD 20771.

T. L. Kucsera, Applied Research Corporation, 8201 Corporate Drive, Lanham, MD 20706.

\author{
(Received February 8, 1988; \\ revised July 31 , 1989;
} accepted July 31, 1989). 